\title{
The differential impact of subjective and objective aspects of social engagement on cardiovascular risk factors
}

\author{
Yumiko Kamiya ${ }^{1 *}$, Brendan Whelan $^{1 \dagger}$, Virpi $^{\text {Timonen }^{2 \dagger}}{ }^{+}$Rose Anne Kenny ${ }^{1 \dagger}$
}

\begin{abstract}
Background: This article provides new insights into the impact of social engagement on CVD risk factors in older adults. We hypothesized that objective (social participation, social ties and marital status) and subjective (emotional support) aspects of social engagement are independently associated with objective measures of cardiovascular risk.

Methods: Data from the English Longitudinal Study on Ageing (ELSA) were analyzed. The effects of social participation, social ties, marital status, and emotional support on hypertension, obesity, high sensitivity C-reactive protein, and fibrinogen were estimated by logistic regression controlling for age, sex, education, physical function, depression, cardiovascular disease, other chronic diseases, physical activity, and smoking.

Results: Social participation is a consistent predictor of low risk for four risk factors, even after controlling for a wide range of covariates. Being married is associated with lower risk for hypertension. Social ties and emotional support are not significantly associated with any of the cardiovascular risk factors.

Conclusion: Our analysis suggests that participation in social activities has a stronger association with CV risk factors than marital status, social ties or emotional support. Different forms of social engagement may therefore have different implications for the biological risk factors involved.
\end{abstract}

\section{Background}

Cardiovascular disease (CVD) is the leading cause of morbidity and mortality in Europe (WHO, 2005), accounting for over 4.3 million deaths each year [1], a figure that amounts to nearly half $(48 \%)$ of all deaths in Europe. Overall CVD is estimated to cost the EU economy $€ 192$ billion a year, of which $€ 110$ billion (57\%) is due to health care costs and $€ 82$ billion (43\%) to productivity losses and informal care [1].

Evidence from the USA prospective studies has suggested that social engagement lowers the incidence of cardiovascular disease and other chronic diseases [2-6]. Social engagement has been shown to have a beneficial effect on several behaviours that affect the risk of cardiovascular disease such as smoking [7-9], smoking cessation $[10,11]$, adherence to medical treatment [12], participation in physical activity $[13,14]$ and diet $[15,16]$.

\footnotetext{
* Correspondence: kamiyay@tcd.ie

† Contributed equally

'Department of Medical Gerontology, Trinity College Dublin, Dublin, Ireland Full list of author information is available at the end of the article
}

Social engagement also influences health through psychological processes. Social contacts can attenuate stressful experiences by helping to solve problems, or by giving a new interpretation of adverse events [17], thereby buffering the harmful effects of stress $[7,18,19]$. Social engagement also modulates cardiovascular reactivity [17] via reduced sympathetic nervous system activity and/or stress-related hormonal activity. Social engagement which attenuates the neuro-endocrine stress response [7,17], influences one's emotional state, giving a sense of purpose, meaning and belonging and reducing the intensity and duration of negative affective states [20].

Few studies have examined the possible differential impact of aspects of social engagement and consequently little is known about which components of social engagement are most protective for cardiovascular disease [21]. Disciplinary differences in research approaches contributed to this outcome. While social scientists have focused on "objective" aspects of relationships such as marital status [22], social networks [2],

C Biomed Central

(c) 2010 Kamiya et al; licensee BioMed Central Ltd. This is an Open Access article distributed under the terms of the Creative Commons Attribution License (http://creativecommons.org/licenses/by/2.0), which permits unrestricted use, distribution, and reproduction in any medium, provided the original work is properly cited. 
contact with network members, and participation in social activities [23], psychologists have focused on subjective aspects of social relationships such as perceived emotional support and loneliness [24]. In addition, data limitations have encouraged researchers to focus on either subjective or objective aspects of social engagement [25].

In a recent meta-analysis, the protective effects of distinct types of social support on the incidence and prognosis of coronary heart disease (CHD) were mixed. While there was evidence that emotional support was protective against the prevalence and disease progression of CHD, the results were unclear for structural support (defined as number of contacts, membership of community groups and marital status) [26].

The aim of this paper is to make a contribution to the literature by examining the effects of social engagement on CV risk factors. Our use of direct measures of health instead of self-perceived (self-reported) health, is a further improvement from previous studies, because direct measures reduce the likelihood of reporting bias errors [27].

In this article, 'social engagement' refers to a combination of objective and subjective measures of the salient aspects of people's 'social' existence. The objective measures are defined by connectedness to other individuals (the number of children, friends and relatives whom the respondent feels are close to him/her) and participation in social groups (affiliation to or membership in religious, voluntary, political, and social associations or activities). The first, we refer as "social ties", and the second as "social participation". The subjective measures comprise of perceptions of available emotional support from spouse, children, relatives and friends. These components are based on previous studies of older individuals [28]. We hypothesized that objective (social participation, social ties and marital status) and subjective (emotional support) aspects of social engagement are independently associated with objective measures of $\mathrm{CV}$ risk.

The risk factors examined here have well-established associations with cardiovascular diseases: hypertension, obesity and two inflammatory markers - fibrinogen, and high sensitivity C-reactive protein (hsCRP). Epidemiological studies have shown that both systolic (SBP) and diastolic blood pressure (DBP) are important cardiovascular risk factors [29]. Obesity, measured by BMI, is an independent predictor of coronary heart disease $[29,30]$. Both high sensitivity CRP and fibrinogen are acute phase inflammation reactants. Prospective studies and meta-analysis have demonstrated that hsCRP [31-34] and fibrinogen $[35,36]$ are strong independent predictors of the risk of cardiovascular disease in healthy individuals and in those with pre-existing CVD. Specifically,
hsCRP is a predictor of frailty [37], a risk factor for the development of arterial fibrillation [38], ischemic stroke [39], and diabetes [40]. Fibrinogen is involved in thrombogenesis and in the stimulation of atherogenenic cell proliferation; elevated levels of fibrinogen are associated with coronary disease and stroke $[41,42]$.

\section{Methods}

\section{Design/participants}

The English Longitudinal Study of Ageing (ELSA) is an ongoing panel study of a nationally representative sample of the English population living in households. The original ELSA cohort consists of men and women born on or before 29 February 1952. The sample was drawn from households that had participated in the Health Survey for England (HSE) in 1998, 1999, and 2001. For the present analyses, data from the first wave (baseline, 2002-2003) and second wave (2004-2005) were used. The first and second wave involved a face-to-face interview. The second wave also included a clinical assessment by a nurse. This is the only wave containing the objective health assessment and blood analysis data that is currently available for public use. Overall, 10,770 participated in wave 1 (response rate $65.7 \%$ ). Of these, 8,688 people participated in wave $2(82 \%)$ and 7,433 participants were willing to have a nurse visit. Of these, 6,649 people consented to a blood sample.

Valid blood samples are available for 5,884 people of which 4,432 (75\%) were fasting. Fasting blood samples were taken for most respondents under the age of 80 except people who had known diabetes and were on treatment, or whose heath the nurse was concerned about. Subjects were considered to have fasted if they had not had food or drink for a minimum of 5 hours prior to the blood test. However, there was no considerable differences in the mean (Chi square test) for those who had fasted (fibrinogen mean $=3.27$ and $\mathrm{SD}=$ 0.0147; hsCRP mean $=2.52$ and $\mathrm{SD}=0.045)$ and for those who had not fasted (fibrinogen mean $=3.33$ and $\mathrm{SD}=0.019$; hsCRP mean $=2.703$ and $\mathrm{SD}=0.058)$. Because this is a prospective population study ( $\mathrm{n}=$ 8,688 ), due to the length of fieldwork (July 2004- July $2005)$ and the overall fieldwork capacity, it was not possible to allow for circadian effects by restricting nurses to, for example, morning-only appointments. While hsCRP has no circadian or seasonal variation $[43,44]$, the literature shows that for fibrinogen the proportion of variation attributed to the diurnal, seasonal, and processing effects was only $2 \%$ [45].

Biological data were missing for participants who did not consent to give blood (participants recently had a blood test, disliked needles or had previous difficulty with venipuncture, $n=993$ ), were ineligible (participants with clotting and bleeding disorders, or taking 
anti-coagulant medication, $\mathrm{n}=351$ ) or for whom attempts to obtain a blood sample were unsuccessful (incomplete/partial sample taken, insufficient blood for test or no suitable/palpable vein/collapsed vein, $\mathrm{n}=$ 360). The analysis of the blood data was carried out in the Royal Victoria Infirmary (Newcastle-upon-Tyne, UK). Both the HSE and ELSA employed the same laboratory and the same guidelines and protocols for the blood analysis. Detailed information on the technicalities of the blood analysis, the internal control, and the external quality assessment are available in the 2004 HSE technical report [46]. Blood samples were analyzed for hsCRP and fibrinogen. Analysis of hsCRP levels from serum was performed using the $\mathrm{N}$ Latex high sensitivity CRP mono immunoassay on the Behring Nephelometer II analyser. The limit of detection was $0.17 \mathrm{mg} / \mathrm{l}$ and the coefficient of variation $(\mathrm{CV})$ was less than $6 \%$ for this assay. Fibrinogen levels were determined using the Organon Teknika MDA 180 analyser, using a modification of the Clauss thrombin clotting method, with a CV of less than $10 \%$. These are acceptable limits in a large population based sample. Blood pressure was recorded as the average of three seated blood pressure readings (Omron HEM-907 blood pressure monitor).

In comparison with the overall sample (Chi square tested), the sub-group of people who donated blood were younger (mean age 66 years old vs. 69 years), had a lower prevalence of morbidity (39.1 vs. $26.2 \%$ ), better self-reported health (75.3\% vs. $60.5 \%)$ and better health behaviours including lower rates of smoking (18.9\% vs. $16.9 \%$ ) and were less sedentary (reported no frequency of physical activity $6.5 \%$ vs. $15 \%$ ). However, social engagement variables were not different between respondents who agreed to blood donation and those for whom blood was not available for analysis.

In order to account for non-response to blood sample, weights were used which aimed at reducing any bias arising from differential non-response between completion of the nurse visit and giving a blood sample [47]. Using these weights allows correction for non-response at interview, nurse visit, and in providing a non-fasting blood sample.

The final weights used thus incorporate adjustment for four levels of attrition/non-response: 1) from initial sample (HSE) to wave $1 ; 2$ ) from wave 1 to wave $2 ; 3$ ) from interview at wave 2 to the nurse visit; and 4) nonresponse to blood donation. These weights attenuate the potential selection biases due to attrition at different stages and should ensure that the weighted data will be representative of the English population living in the community who are over 50 years-old [48]. Details on the calculations of weights are presented in the ELSA technical report [48].

\section{Measurements}

\section{Cardiovascular risk markers}

Cardiovascular risk variables were dichotomized. Hypertension is defined as SBP and DBP $\geq 140 / 90 \mathrm{mmHg}$ [49] or $\mathrm{SBP} \geq 140$ (isolated systolic hypertension) or using hypertensive medication. Obesity was measured by body mass index (BMI), which was dichotomized by means of a cut-off point of $\geq 30 \mathrm{~kg} / \mathrm{m} 2$. For both hsCRP and fibrinogen [50], clinical cut-off points were used; $h s C R P>3.0$ $\mathrm{mg} / \mathrm{l}$ was interpreted as high risk as it corresponds approximately to the highest tertile of hsCRP in the adult population [50]. Cases with hsCRP higher than 10 $\mathrm{mg} / \mathrm{L}$ were excluded from the hsCRP analysis because such levels reflect an acute infection or inflammation other than those due to cardiovascular disease [51]. For fibrinogen, values $>4.0 \mathrm{~g} / \mathrm{L}$ are a valid clinical cut-off and correspond to the highest quartile concentration in the adult population [52].

\section{Social engagement}

Three different dimensions of social engagement were examined. Social participation was measured as a count of seven activities in which the respondent reported current membership or participation in any of a list of groups and associations divided into: (1) political, trade union or environmental group; (2) tenants' groups, residents' groups or neighbourhood watch; (3) church or other religious organization; (4) charitable associations; (5) an education, arts or music group or evening class; (6) social club (e.g. Rotary Club, elderly lunch group, women's group); and (7) any other organisations, clubs or societies. The social participation raw score therefore ranges from 0 to 7 . This was standardized as a Z-score. Scores range from -0.899 to 4.202 with weighted mean of -0.087 ( $\mathrm{SD}=0.953)$. Higher scores indicate greater social participation. Social ties were measured by a count of the number of children, relatives and friends the participant felt close to ("How many of your children/relatives/friends would you say you have a close relationship with?"). The final score was standardized and its value was averaged across the ties that were relevant for a given respondent. Scores range from -1.256 to 1.533 with weighted mean of $-0.090(\mathrm{SD}=0.301)$. Emotional support from spouse, children, relatives and friends was measured by the following three questions: a) How much respondents feel their spouse/partner (children/relatives/friends) understand(s) their feelings; b) How much respondents can rely on their spouse/ partner (children/relatives/friends) if they have a serious problem; and c) How much respondents can open up to their spouse/partner (children/relatives/friends) if they need to talk. The responses for each item range from 0 (not at all) to 3 (a lot). Responses to all twelve questions were added up to a summary score (Cronbach's alpha was 0.88$)$. The emotional support scale was constructed 
by standardizing and then averaging across the relevant item scores. Standardized scores range from -2.409 to 0.1838 with weighted mean of -0.174 (SD =0.554). Marital status was dichotomized as married (or cohabiting) and not married (never married, separated or divorced, and widowed).

Demographic and socio-economic variables included age (in years), age squared, sex (male as reference category), and education measured as the highest qualification participants obtained, and categorized into four groups (no education, primary, secondary and tertiary level).

\section{Health behaviours}

Smoking was coded as never smoked and ever smoked (ex-smoker or current smoker). Self-reported physical exercise was classified as none, light, moderate and vigorous activity at least once a week.

\section{Co-morbidity}

Physical function was assessed by dichotomizing the Activities of Daily Living into "0 ADL", reporting no ADL difficulties and " $\geq 1$ ADL", reporting one or more ADL difficulties. Known cardiovascular disease was assessed by self-reported angina, myocardial infarction, diabetes, stroke, heart failure, heart murmur, abnormal heart rhythm, and ischaemic heart disease. Other major chronic diseases include self-reported chronic lung disease, asthma, arthritis, osteoporosis, cancer, and Parkinson's disease. These variables are dichotomized into "0 conditions" and " $\geq 1$ conditions". Depression was measured by the 8-item Center for Epidemiologic Studies Depression Scale (CES-D) with a cut-off point of 3 or more depressive symptoms [53] ( $<3=$ non depressive, $\geq 3=$ depressive).

\section{Statistical Analysis}

We used Spearman's rho to test for independence among social engagement variables. The correlations between social participation and social ties $(\mathrm{r}=0.15, \mathrm{p}<$ $0.001)$, and social participation and emotional support ( $\mathrm{r}$ $=0.19, \mathrm{p}<0.001$ ) were weak in strength. Correlation between social ties and emotional support was moderate in strength $(\mathrm{r}=0.32, \mathrm{p}<0.001)$. Correlations between marital status and emotional support was moderate in strength $(\mathrm{r}=0.29, \mathrm{p}<0.001)$, while correlation between marital status and social participation $(\mathrm{r}=0.04, \mathrm{p}<$ 0.001 ), and marital status and social ties were weak in strength $(\mathrm{r}=0.05, \mathrm{p}<0.001)$. Therefore, objective and subjective measurements were not strongly correlated and, since they are conceptually distinct, we expect that these four dimensions would have independent associations with cardiovascular risk markers.

Using logistic regression, each cardiovascular risk factor (hypertension, BMI, fibrinogen, and hsCRP) at wave 2 was regressed on the complete set of social engagement variables at baseline (social participation, social ties, marital status and emotional support). The independent effect of each of the social engagement variables was examined by putting all the social engagement variables and confounding factors (age, gender, education, co-morbidity and behavioral risk factors) into a single model. Seasonality was adjusted for fibrinogen. Age squared was used to test for the non-linear relationship between age and the outcome variables, and an interaction term between sex and age was also included. The result of Goodness-of-fit tests (such as Akaike Information Criterion- AIC and Bayesian Information Criterion-BIC) supported the model with interaction and quadratic term over the nested model (with no interaction and quadratic term). Data were weighted for panel attrition.

\section{Results}

Table 1 presents characteristics of the sample at baseline. The sample was composed of $53.4 \%$ women and $46.6 \%$ men. The median age was 65.4 years (66.3 and 64.3 years for women and men respectively). Sixty seven percent were married, and $40.5 \%$ had a primary education. Thirty-seven percent reported no social participation, and $15.1 \%$ of the respondents reported that they did not have children, relatives or friends that they felt close to. Nighteen percent reported having cardiovascular morbidity, $39.7 \%$ reported having non-cardiovascular chronic conditions, $29.9 \%$ reported difficulties with at least one ADL, and $22.9 \%$ had depressive symptoms. Approximately $8 \%$ were relatively sedentary, reporting no physical activity and $17.5 \%$ were smokers.

Tables 2 and 3 shows the odds ratios (OR) and 95\% confidence intervals (CIs) from logistic regression. The results of these tables show whether baseline social engagement predicted the cardiovascular risk factors at follow-up. First, we fitted a model controlling for age, gender, education and co-morbidity (physical function, depression, cardiovascular and chronic disease). In addition, behavioral risk factors (smoking, and physical activity) known as confounders or mediators were adjusted in model 2 .

In model 1, social participation was inversely associated with all four of the CV risk markers $(\mathrm{p}<0.05)$. For example, an increase of one standard deviation in social participation was associated with about $7 \%$ lower odds of having hypertension, $11 \%$ lower odds of being obese, and $10 \%$ and $12 \%$ lower odds of having higher levels of hsCRP and fibrinogen, respectively. Being married was inversely associated with hypertension and fibrinogen; being married would reduce the odds of having hypertension by $15 \%$, and the odds of elevated levels of fibrinogen by $16 \%$.

Model 2 assesses the roles of behavioral factors as potential mediators or confounders of the relationship 
Table 1 Descriptive characteristics of the sample at baseline and CV risk factors at wave 2

\begin{tabular}{|c|c|}
\hline Variable & Percent/Mean (SD) \\
\hline \multicolumn{2}{|l|}{ Social engagement } \\
\hline Social participation & $1.23(1.37)$ \\
\hline Social ties & $6.42(5.22)$ \\
\hline Emotional support & $2.82(3.51)$ \\
\hline \multicolumn{2}{|c|}{ Demographic and socio-economic variables } \\
\hline \multicolumn{2}{|l|}{ Age (\%) } \\
\hline $50-60$ years & 37.27 \\
\hline $60-70$ years & 28.42 \\
\hline 70-80 years & 22.49 \\
\hline $80+$ years & 11.82 \\
\hline Mean Age & $65.35(10.60)$ \\
\hline Currently married (\%) & 66.70 \\
\hline Female (\%) & 53.70 \\
\hline \multicolumn{2}{|c|}{ Education: levels of education attained } \\
\hline tertiary & 22.91 \\
\hline secondary & 27.87 \\
\hline primary & 40.50 \\
\hline no education & 8.72 \\
\hline \multicolumn{2}{|l|}{ Co-morbidity } \\
\hline Have Depression (8 items CES-D) & 22.90 \\
\hline No chronic disease* & 60.21 \\
\hline No CVD** & 81.16 \\
\hline No limitations with ADLs & 70.10 \\
\hline \multicolumn{2}{|l|}{ Health Behaviours } \\
\hline Never smoked & 82.46 \\
\hline \multicolumn{2}{|l|}{ Physical activity } \\
\hline none & 8.24 \\
\hline light & 15.75 \\
\hline moderate & 48.65 \\
\hline vigorous & 27.36 \\
\hline \multicolumn{2}{|l|}{ Cardiovascular variables } \\
\hline \multicolumn{2}{|l|}{ Systolic and diastolic blood pressure } \\
\hline Mean systolic BP (mmHg) & $135.4(19.0)$ \\
\hline Mean diastolic BP (mmHg) & $74.9(11.3)$ \\
\hline Hypertension (\%) & 38.78 \\
\hline Body Mass Index (>30 kg/m2) & 28.90 \\
\hline Mean hsCRP (mg/l) & $2.55(2.16)$ \\
\hline Mean Fibrinogen ( $g / l)$ & $3.2(0.7)$ \\
\hline
\end{tabular}

Note: For hsCRP and fibrinogen, $\mathrm{n}=5884$. For all other variables, $\mathrm{n}=7433$. *chronic lung diasese, arthritis, osteoporosis, cancer, parkinson's disease. **angina, diabetes, myocardial infection, stroke, heart failure, heart murmur, abnormal heart rhythm, valvular heart disease, ischaemic heart disease.

between social engagement and CV risk factors. When behavioural factors are controlled for, the associations between social participation and hypertension and BMI remained unchanged. However, behavioral factors attenuated the results for hsCRP (from 10\% to 7\%), and for fibrinogen (from $12 \%$ to $8 \%$ ).

We also performed analysis without adjusting for the weights (results upon the request). The results were similar and remained significant for those variables discussed in the main text. In addition, to examine whether social engagement protects against $\mathrm{CV}$ risk factors for those with pre-existing CVD, we constructed a version of model 2 with interaction terms. In those who had a pre-existing CVD, social ties had a protective effect by lowering the hsCRP level $(\mathrm{OR}=0.84,95 \% \mathrm{CI}$ : 0.716 0.995 ) and emotional support increased the odds of being obese $(\mathrm{OR}=1.58$; 95\% CI: $0.998-2.50)$. The other dimensions of social engagement such as marital status and social participation were not significant.

\section{Discussion and Conclusions}

Previous studies $[5,19,54,55]$ examining objective aspects of social engagement (i.e. social participation and social ties) found no consistent association between inflammatory markers (hsCRP and fibrinogen) for older and younger women and younger men. The authors recommended that subjective aspects of social engagement (such as emotional support) should be addressed in further studies in order to provide insight into the role of inflammatory markers as biological mediators between social engagement and cardiovascular disease. In addition, the way that the social engagement variable was constructed in the previous studies made it difficult to identify which particular aspects of people's social relationships are associated with cardiovascular disease. This paper addressed this issue by incorporating both objective and subjective measurements. Furthermore, this paper explored how social engagement may protect against cardiovascular disease by examining its association with cardiovascular risk factors.

Results indicate that within the objective measures, behavioral factors may mediate the relationship between social participation and inflammatory markers i.e., the risks of having higher concentrations of inflammatory markers may operate partially through health behaviours. Conversely, for BMI and hypertension, social participation seems to operate distinctly from behavioral factors and is an independent predictor of CV risk markers.

Marriage is associated with hypertension and it is not mediated by behavioral factors. Contrary to what has been suggested in the literature, social ties and emotional support were not significant for $\mathrm{CV}$ risk factors [19]. We also tested whether emotional support mediates the relationship between social ties and CV risk factors, but could not find strong evidence of such mediation. Additional analysis was performed (not shown) to include measures of loneliness (only available at wave 2). However, controlling for depression (CES-D minus the loneliness item), the effect of loneliness was not significant.

Successive meta-analysis and prospective studies show evidence that depression is associated with an increased 
Table 2 Logistic regression models for hsCRP and fibrinogen

\begin{tabular}{|c|c|c|c|c|}
\hline & & & & \\
\hline & Model 1 & Model 2 & Model 1 & Model 2 \\
\hline & OR $(95 \% \mathrm{Cl})$ & OR $(95 \% \mathrm{Cl})$ & OR (95\% Cl) & OR $(95 \% \mathrm{Cl})$ \\
\hline Age & 1.156 & 1.186 & 1.202 & 1.222 \\
\hline & $(1.082-1.234)^{* *}$ & $(1.109-1.268)^{* *}$ & $(1.129-1.279)^{* *}$ & $(1.148-1.303)^{* *}$ \\
\hline Age squared & 0.999 & 0.999 & 0.999 & 0.999 \\
\hline & $(0.999-1.000)^{* *}$ & $(0.998-0.999)^{* *}$ & $(0.998-0.999)^{* *}$ & $(0.998-0.999)^{* *}$ \\
\hline Female & 2.923 & 3.025 & 1.772 & 1.765 \\
\hline & $(1.309-6.527)^{* *}$ & $(1.338-6.843)^{* *}$ & $(0.795-3.953)$ & $(0.781-3.993)$ \\
\hline Age ${ }^{*} \operatorname{sex}$ & 0.986 & 0.985 & 0.993 & 0.994 \\
\hline & $(0.974-0.998)^{*}$ & $(0.974-0.997)^{*}$ & $(0.982-1.006)$ & $(0.982-1.006)$ \\
\hline Education & 0.884 & 0.903 & 0.872 & 0.892 \\
\hline & $(0.825-0.947)^{* *}$ & $(0.842-0.968)^{* *}$ & $(0.795-3.953)^{* *}$ & $(0.831-0.957)^{* *}$ \\
\hline Married & 0.908 & 0.947 & 0.875 & 0.927 \\
\hline & $(0.791-1.043)$ & $(0.823-1.091)$ & $(0.765-1.001)^{*}$ & $(0.807-1.063)$ \\
\hline Social participation & 0.902 & 0.934 & 0.889 & 0.929 \\
\hline & $(0.846-0.962)^{* *}$ & $(0.875-0.997)^{*}$ & $(0.834-0.948)^{* *}$ & $(0.871-0.992)^{*}$ \\
\hline Social ties & 0.971 & 0.97 & 0.976 & 0.973 \\
\hline & $(0.912-1.034)$ & $(0.911-1.034)$ & $(0.917-1.038)$ & $(0.914-1.036)$ \\
\hline Emotional support & 1.025 & 1.041 & 0.925 & 0.95 \\
\hline & $(0.877-1.199)$ & $(0.885-1.223)$ & $(0.801-1.067)$ & $(0.818-1.102)$ \\
\hline $\mathrm{ADL}$ & 1.422 & 1.283 & 1.527 & 1.402 \\
\hline & $(1.231-1.642)^{* *}$ & $(1.105-1.490)^{* *}$ & $(1.329-1.755)^{* *}$ & $(1.213-1.621)^{* *}$ \\
\hline Depression & 1.007 & 0.960 & 1.115 & 1.049 \\
\hline & $(0.869-1.166)$ & $(0.826-1.115)$ & $(0.968-1.283)^{*}$ & $(0.9081-1.212)$ \\
\hline CVD & 0.983 & 0.940 & 1.083 & 1.041 \\
\hline & $(0.838-1.153)$ & $(0.799-1.106)$ & $(0.929-1.263)$ & $(0.890-1.217)$ \\
\hline Chronic disease & 1.269 & 1.224 & 1.118 & 1.081 \\
\hline & $(1.158-1.390)^{* *}$ & $(1.115-1.344)^{* *}$ & $(1.024-1.221)^{*}$ & $(0.987-1.182)$ \\
\hline Never smoked & & 0.643 & & 0.563 \\
\hline & & $(0.549-0.753)^{* *}$ & & $(0.4832-0.655)^{* *}$ \\
\hline Physical activity & & 0.851 & & 0.851 \\
\hline & & $(0.805-0.899)^{* *}$ & & $(0.805-0.889)^{* *}$ \\
\hline Seasonality & & & 1.196 & 1.190 \\
\hline & & & $(1.136-1.258)^{* *}$ & $(1.130-1.254)^{* *}$ \\
\hline
\end{tabular}

$95 \%$ confidence intervals in parentheses.

*significant at 5\%; ** significant at $1 \%$.

Model 1 controls for age, gender, education, and comorbidity (physical ability, depression, chronic conditions and cardiovascular disease).

Model 2 contains all adjustments from Model 1 with addition of health behaviours.

risk of all-cause and cardiovascular death and that this risk is particularly marked in depressive participants with co-morbid CHD [56-59]. However, the association between inflammatory markers and depression have been unclear [60]. In this study, only fibrinogen was modestly associated with depression but not hsCRP. Other studies, such as the Longitudinal Aging Study Amsterdam found similar results, with no association between CRP and depression [61]. Therefore, the mechanisms linking depression to inflammatory markers are still poorly understood. Meta-analysis in the future would help to clarify these contradictory findings. Some limitations of how depressive symptoms were measured in ELSA need to be also considered. The reduced 8 items of CES-D scale assesses depressive symptoms rather than clinical depression. CES-D is therefore not a diagnostic test of depression but poor scores are indicative of possible depression.

A recent study on social participation [62] did not find any consistent association with $\mathrm{CV}$ risk factors. However, the study compared the mean scores of the CV risk markers by social participation adjusted only for age and social class. Our study adjusted for various indicators of comorbidity and behavioral factors to reduce the likelihood that the observed relationship between social engagement and $\mathrm{CV}$ risk factors was a spurious one. 
Table 3 Logistic regression models for hypertension and BMI

\begin{tabular}{|c|c|c|c|c|}
\hline & & & & \\
\hline & Model 1 & Model 2 & Model 1 & Model 2 \\
\hline & OR $(95 \% \mathrm{Cl})$ & OR $(95 \% \mathrm{Cl})$ & OR $(95 \% \mathrm{Cl})$ & OR (95\% Cl) \\
\hline Age & 1.121 & 1.114 & 1.123 & 1.139 \\
\hline & $(1.064-1.182)^{* *}$ & $(1.056-1.175)^{* *}$ & $(1.047-1.203)^{* *}$ & $(1.060-1.224)^{* *}$ \\
\hline Age squared & 0.999 & 0.999 & 0.9989 & 0.999 \\
\hline & $(0.999-1.000)^{* *}$ & $(0.999-1.000)^{* *}$ & $(0.998-0.999)^{* *}$ & $(0.998-0.999)^{* *}$ \\
\hline Female & 0.180 & 0.183 & 0.5435 & 0.558 \\
\hline & $(0.095-0.340)^{* *}$ & $(0.096-0.347)^{* *}$ & $(0.253-1.211)$ & $(0.257-1.211)$ \\
\hline Age $^{*} \operatorname{sex}$ & 1.022 & 1.021 & 1.0119 & 1.011 \\
\hline & $(1.012-1.032)^{* *}$ & $(1.012-1.031)^{* *}$ & $(1.000-1.023)^{*}$ & $(0.999-1.023)$ \\
\hline Education & 0.937 & 0.933 & 0.8890 & 0.887 \\
\hline & $(0.887-0.990)^{*}$ & $(0.883-0.987)^{*}$ & $(0.836-0 . .945)^{* *}$ & $(0.833-0.944)^{* *}$ \\
\hline Married & 0.859 & 0.846 & 1.1386 & 1.111 \\
\hline & $(0.768-0.961)^{* *}$ & $(0.755-0.948)^{* *}$ & $(1.005-1.289)^{*}$ & $(0.978-1.262)$ \\
\hline Social participation & 0.934 & 0.930 & 0.9026 & 0.897 \\
\hline & $(0.888-0.982)^{* *}$ & $(0.884-0.979)^{* *}$ & $(0.852-0.956)^{* *}$ & $(0.846-0.952)^{* *}$ \\
\hline Social ties & 0.992 & 0.991 & 1.0577 & 1.061 \\
\hline & $(0.945-1.042)$ & $(0.943-1.041)$ & $(1.002-1.116)^{*}$ & $(1.005-1.120)$ \\
\hline Emotional support & 1.067 & 1.092 & 0.9474 & 0.968 \\
\hline & $(0.944-1.206)$ & $(0.963-1.238)$ & $(0.826-1.086)$ & $(0.840-1.116)$ \\
\hline$A D L$ & 1.052 & 1.051 & 1.6548 & 1.542 \\
\hline & $(0.933-1.185)$ & $(0.929-1.189)$ & $(1.456-1.881)^{* *}$ & $(1.350-1.762)^{* *}$ \\
\hline Depression & 0.942 & 0.938 & 0.9364 & 0.921 \\
\hline & $(0.836-1.060)$ & $(0.832-1.058)$ & $(0.821-1.068)$ & $(0.805-1.053)$ \\
\hline CVD & 0.843 & 0.832 & 1.5589 & 1.479 \\
\hline & $(0.743-0.957)^{* *}$ & $(0.731-0.946)^{* *}$ & $(1.361-1.785)^{* * *}$ & $(1.288-1.699)^{* *}$ \\
\hline Chronic disease & 0.966 & 0.964 & 1.2305 & 1.215 \\
\hline & $(0.896-1.042)$ & $(0.894-1.040)$ & $(1.134-1.335)^{* *}$ & $(1.118-1.320)^{* *}$ \\
\hline Never smoked & & 1.033 & & 1.727 \\
\hline & & $(0.910-1.173)$ & & $(1.005-1.289)^{* *}$ \\
\hline Physical activity & & 0.995 & & 0.839 \\
\hline & & $(0.953-1.039)$ & & $(0.799-0.882)^{* *}$ \\
\hline
\end{tabular}

95\% confidence intervals in parentheses.

*significant at $5 \%$; ** significant at $1 \%$.

Model 1 controls for age, gender, education, and comorbidity (physical ability, depression, chronic conditions and cardiovascular disease).

Model 2 contains all adjustments from Model 1 with addition of health behaviours.

The findings suggest that participation in social, civic or political activities may have an important effect on lowering CV risk factors. Previous research has found that social participation has an impact on physical and mental health [63-65], survival at older ages [66], and is inversely associated with plasma fibrinogen $[67,68]$. Participation in political, social or civic activities provides social contacts and gives rise to meaningful social roles which in turn provide a sense of value, belonging and attachment in the community [28]. Social participation may give meaning and purpose to life through the fulfillment of various social roles [69], thus lowering the levels of psychological distress [66]. Social participation may facilitate access to health information and services, and provide access to resources such as information, transportation, and emotional support [21]. It may even exert social control by encouraging health promoting behaviors such as exercise, diet or discouraging health damaging behaviors such as smoking, excessive eating, alcohol consumption and drug abuse [70].

The results also show that marriage was associated with hypertension. The protective relationship between marriage and morbidity/mortality from cardiovascular disease has been established in many studies [71]. Marriage may reduce stress and stress related illness [22], by attenuating the effects of stress on cardiovascular hyperreactivity and on exaggerated sympathetic nervous system activity [71].

This study has both strengths and limitations. Strengths include a large representative sample of the 
non-institutionalized older population from which the findings can be generalized, the use of four separate indicators of social engagement, and the careful direct measurement of a range of relevant and previously validated cardiovascular risk factors. The limitations are firstly that causality cannot be inferred from cross-sectional data analysis (necessitated by the fact that availability of health measurement and blood data is currently limited to a single wave of the study). Secondly, despite the fact that we controlled for physical activities and that social participation was not correlated with physical activities, one could argue that social participation is actually measuring physical activities in ways not otherwise controlled for. We tested whether some of the social participation items such as participation in tenants' groups or neighbourhood watch might incorporate some amount of physical activity. A correlation test was carried out on the relationship between physical activities and each type of social participation, but only the item referring to "attending education, arts or music groups or evening class" was weakly correlated $(\mathrm{r}=$ $0.127, \mathrm{p}<0.001)$. The other activities were not correlated. In addition, in model 2 presented in the paper, social engagement and physical activity were entered simultaneously and both variables were significant. This result adds to our confidence that these variables are independent predictors of $\mathrm{CV}$ risk factors and the effect of social participation is not due to the impact of physical activity. Third, although we adjusted for an extensive range of health factors, one could argue that social participation is actually measuring health status in ways not otherwise controlled for. Future analyses of forthcoming panel data will allow us to explore this and draw stronger causal inferences from further waves.

This article has explored the relationships between different aspects of social engagement and cardiovascular risk factors. Examination of different dimensions of social engagement suggests that we can identify more precise biological pathways through which social engagement influences cardiovascular disease. The analysis advanced here, it is hoped, will be of relevance to scholars working at the intersection of the social and biomedical sciences, who are seeking to understand the complex interactions between social engagement and CVD.

\section{Author details}

'Department of Medical Gerontology, Trinity College Dublin, Dublin, Ireland. ${ }^{2}$ School of Social Work \& Social Policy, Trinity College Dublin, Dublin, Ireland.

\section{Authors' contributions}

YK performed the statistical analysis, interpreted the results and drafted the manuscript. BJW and VT participated in interpretation of the results and drafting the manuscript. RK was responsible for the study interpretation and manuscript write-up. All authors read and approved the final manuscript.

\section{Competing interests}

The authors declare that they have no competing interests.

Received: 30 July 2010 Accepted: 2 November 2010

Published: 2 November 2010

\section{References}

1. Allender S, Scarborough P, Peto V, Rayner M, Leal J, Luengo-Fernandez R, Gray A: European cardiovascular disease statistics 2008. The European Heart Network (EHN); 2008.

2. Berkman LF, Syme SL: Social networks, host resistance, and mortality: a nine-year follow-up study of Alameda County residents. Am J Epidemiol 1979, 109(2):186-204

3. House JS, Landis K, Umberson D: Social relationships and health. Science 1988, 241:540-545

4. Seeman T, Kaplan G, Knudsen L, et al: Social network ties and mortality among the elderly in the Alameda County Study. Am J Epidemiol 1987, 126:714-723.

5. Ford E, Loucks E, Berkman L: Social integration and concentrations of Creactive protein among US adults. Ann Epidemiol 2006, 16(2):78-84.

6. Eng P, Rimm E, Fitzmaurice G, Kawachi I: Social ties and change in social ties in relation to subsequent total and cause-specific mortality and coronary heart disease incidence in men. American Journal of Epidemiology 2002, 155(8):700-709.

7. Cohen S: Psychosocial models of the role of social support in the etiology of physical disease. Health Psychol 1988, 7(3):269-297.

8. Broman C: Social relationships and health-related behavior. J Behav Med 1993, 16:335-350.

9. Broman CL: Social relationships and health-related behavior. Journal of Behavioral Medicine 1993, 16(4):335-350.

10. Mermelstein $\mathrm{R}$, Cohen $\mathrm{S}$, Lichtenstein $\mathrm{E}$, et al: Social support and smoking cessation and maintenance. J Consult Clin Psychol 1986, 54:447-453.

11. Murray R, Johnston J, Dolce J, et al: Social support for smoking cessation and abstinence: the Lung Health Study. Addict Behav 1995, 20:159-170.

12. Sanson-Fisher $\mathrm{R}$, Clover $\mathrm{K}$ : Compliance in the treatment of hypertension: a need for action. Am J Hypertens 1995, 8(10):82S-88S.

13. Orth-Gomer K, Rosengren A, Wilhelmsen L: Lack of social support and incidence of coronary heart disease in middle-aged Swedish men. Psychosom Med 1993, 55(1):37-43.

14. Kawachi I, Colditz G, Ascherio A, et al: A prospective study of social networks in relation to total mortality and cardiovascular disease in men in the USA. J Epidemiol Community Health 1996, 50:245-251.

15. McIntosh W, Shifflett P, Picou J: Social support, stressful events, strain, dietary intake, and the elderly. Med Care 1989, 27(2):140-153.

16. Toner $\mathrm{H}$, Morris $\mathrm{J}$ : A social-psychological perspective of dietary quality in later adulthood. J Nutr Elder 1992, 11(4):35-53.

17. Cohen S: Social relationships and health. Am Psychol 2004, 59(8):676-684.

18. Uchino BN: Social support and health: a review of physiological processes potentially underlying links to disease outcomes. I Behav Med 2006, 29(4):377-387.

19. Loucks EB, Berkman LF, Gruenewald TL, Seeman TE: Social integration is associated with fibrinogen concentration in elderly men. Psychosom Med 2005, 67(3):353-358.

20. Thoits PA: Life stress, social support, and psychological vulnerability: epidemiological considerations. J Community Psychol 1982, 10(4):341-362

21. Cornwell EY, Waite LJ: Social Disconnectedness, Perceived Isolation, and Health among Older Adults. Journal of Health and Social Behavior 2009, 50:31-48.

22. Lillard L, Waite L: Til Death Do Us Part: Marital Disruption and Mortality. American Journal of Sociology 1995, 100:1131-1156.

23. Thoits PA, Hewitt LN: Volunteer Work and Well-Being. Journal of Health and Social Behavior 2001, 42:115-131.

24. Cacioppo JT, Hughes ME, Waite L, Hawkley LC, Thisted RA: Loneliness as a Specific Risk Factor for Depressive Symptoms: Cross-Sectional and Longitudinal Analyses. Psychology and Aging 2006, 21:140-151.

25. House J: Social Isolation Kills, But How and Why? Psychosomatic Medicine 2001, 63:273-274.

26. Barth J, Scheneider $S$, Känel Rv: Lack of social support in the aetiology and prognosis of coronary heart disease: a systematic review and metaanalysis. Psychosomatic Medicine 2010, 72:229-238. 
27. Kristensen P: Bias from Nondifferential but Dependent Misclassification of Exposure and Outcome. Epidemiology 1992, 3(3):210-215.

28. Berkman LF, Kawachi I: Social Epidemiology. New York: Oxford University Press; 2000.

29. Benetos A, Thomas F, Safar ME, Bean KE, Guize L: Should diastolic and systolic blood pressure be considered for cardiovascular risk evaluation: a study in middle-aged men and women? Journal of the American College of Cardiology 2001, 37(1):163-168.

30. Eckel RH: Obesity and Heart Disease A Statement for Healthcare Professionals From the Nutrition Committee, American Heart Association. Circulation 1997, 96:3248-3250.

31. Ridker PM: High-sensitivity C-reactive protein: potential adjunct for global risk assessment in the primary prevention of cardiovascular disease. Circulation 2001, 103(13):1813-11818.

32. Cook N, Buring J, Ridk P: The effect of including C-reactive protein in cardiovascular risk prediction models for women. Annals of internal medicine 2006, 4(145):21-29.

33. Ridker PMGR, Hennekens CH: C-reactive protein adds to the predictive value of total and $\mathrm{HDL}$ cholesterol in determining risk of first myocardial infarction. Circulation 1998, 97:2007-2011.

34. Ridker PM, Hennekens CH, Buring JE, Rifai N: C-Reactive Protein and Other Markers of Inflammation in the Prediction of Cardiovascular Disease in Women. New England Journal Medicine 2000, 342:836-843.

35. Maresca G, Blasio AD, Marchioli R, Minno GD: Measuring plasma fibrinogen to predict stroke and myocardial infarction. Arteriosclerose Thrombose Vascular Biology 1999, 19:1368-1377.

36. Collaboration FS, Kaptoge S, White IR, GThompson S, Wood AM, Lewington S, Lowe GD, Danesh J: Associations of plasma fibrinogen levels with established cardiovascular disease risk factors, inflammatory markers, and other characteristics: individual participant meta-analysis of 154,211 adults in 31 prospective studies: the fibrinogen studies collaboration. American journal of epidemiology 2007, 166(8):867-79, Epub 2007 Sep 4., 15(8):867-879.

37. Puts MT, Visser M, Twisk JW, Deeg DJ, Lips P: Endocrine and inflammatory markers as predictors of frailty. Clin Endocrinol (Oxf) 2005, 63(4):403-411.

38. Aviles RJ, Martin DO, Apperson-Hansen C, Houghtaling PL, Rautaharju P, Kronmal RA, Tracy RP, Van Wagoner DR, Psaty BM, Lauer MS, et al: Inflammation as a risk factor for atrial fibrillation. Circulation 2003, 108(24):3006-3010

39. Cao JJ, Thach C, Manolio TA, Psaty BM, Kuller LH, Chaves PH, Polak JF, Sutton-Tyrrell K, Herrington DM, Price TR, et al: C-reactive protein, carotid intima-media thickness, and incidence of ischemic stroke in the elderly: the Cardiovascular Health Study. Circulation 2003, 108(2):166-170.

40. Barzilay Jl, Abraham L, Heckbert SR, Cushman M, Kuller LH, Resnick HE, Tracy RP: The relation of markers of inflammation to the development of glucose disorders in the elderly: the Cardiovascular Health Study. Diabetes 2001, 50(10):2384-2389.

41. Di Napoli M, Singh P: Is plasma fibrinogen useful in evaluating ischemic stroke patients?: why, how, and when. Stroke 2009, 40(5):1549-1552.

42. Collaboration FS, Kaptoge S, White I, Thompson S, Wood A, Lewington S, Lowe G, Danesh J: Associations of plasma fibrinogen levels with established cardiovascular disease risk factors, inflammatory markers, and other characteristics: individual participant meta-analysis of 154,211 adults in 31 prospective studies: the fibrinogen studies collaboration. American Journal of Epidemiology 2007, 166(8):867-879.

43. Charuruks N, Laohajinda B, Rujiwanitgun S, Chaiworaporn M: Circulation J. Reference value for C-reactive protein and its distribution pattern in Thai adults. Circulation 2005, 69(3):339-344.

44. Meier-Ewert HK, Ridker PM, Rifai N, Price N, Dinges DF, Mullington JM: Absence of diurnal variation of $\mathrm{C}$-reactive protein concentrations in healthy human subjects. Clinical Chemistry 2001, 47(30):426-430.

45. Rudnicka AR, Rumley A, Lowe G, Strachan D: Diurnal, seasonal, and bloodprocessing patterns in levels of circulating fibrinogen, fibrin D-dimer, Creactive protein, tissue plasminogen activator, and von Willebrand factor in a 45-year-old population. Circulation 2007, 115(8):996-1003.

46. Graig R, Deverill C, Pickering K: Quality Control of blood saliva and urine analytes. In Health Survey for England 2004, Methodology and Documentation. Volume 2. Edited by: Mindell J KS. London: The Information Center; 2006:34-41
47. Taylor R, LCC LC, Lessof C: Health, Wealth and Lifestyles of the Older Population in England; The English Longitudinal Study of Ageing, Technical Report. London: National Centre for Social Research; 2007.

48. Cheshire H, Cox K, Lessof C, Taylor R: Methodology. In Retirement, Health and Relationships of the Older Population in England: the 2004 English Longitudinal Study of Ageing. Edited by: Banks J, Breeze E, Lessof C, Nazroo J. London: The Institute for Fiscal Studies; 2000.

49. NIH: The Sixth Report of the Joint National Committee on Prevention, Detection, Evaluation, and Treatment of High Blood Pressure. National Institutes of Health, National Heart, Lung, and Blood Institute National High Blood Pressure Education Program; 1997.

50. Pearson TA, Mensah GA, Alexander RW, Anderson JL, Cannon RO, Criqui M, Fadl YY, Fortmann SP, Hong Y, Myers GL, et al: Markers of Inflammation and Cardiovascular Disease: Application to Clinical and Public Health Practice: A Statement for Healthcare Professionals From the Centers for Disease Control and Prevention and the American Heart Association. Circulation 2003, 107:499-511.

51. Ridker P: C-reactive protein: a simple test to help predict risk of heart attack and stroke. Circulation 2003, 23(108):81-85.

52. Koenig W: Fibrinogen in cardiovascular disease: an update. Thromb Haemost 2003, 89:601-609.

53. Steffick D: Documentations of affective functioning measures in the Health and Retirement Study. HRS/AHEAD Documentation Report DR-005 Ann Arbor, MI: Survey Research Center University of Michigan; 2000.

54. Loucks EB, Berkman LF, Gruenewald TL, Seeman TE: Relation of social integration to inflammatory marker concentrations in men and women 70 to 79 years. Am J Cardiol 2006, 97(7):1010-1016.

55. Loucks EB, Sullivan LM, D'Agostino RB Sr, Larson MG, Berkman LF, Benjamin EJ: Social networks and inflammatory markers in the Framingham Heart Study. J Biosoc Sci 2006, 38(6):835-842.

56. Nabi H, Shipley M, Vahtera J, Hall M, Korkeila J, Marmot M, Kivimäki M, Singh-Manoux A: Effects of depressive symptoms and coronary heart disease and their interactive associations on mortality in middle-aged adults: the Whitehall II cohort study. Heart 2010, 96(20):1645-50.

57. Heather Lett S, Blumenthal JA, Babyak MA, Sherwood A, Strauman T, Robins C, Newman MF: Depression as a Risk Factor for Coronary Artery Disease: Evidence, Mechanisms, and Treatment. Psychosomatic Medicine 2004, 66:305-315.

58. Rugulies R: Depression as a predictor for coronary heart disease - A review and meta-analysis. Am J Prev Med 2002, 23(1):51-61.

59. Nicholson A, Kuper $\mathrm{H}$, Hemingway $\mathrm{H}$ : Depression as an aetiologic and prognostic factor in coronary heart disease: a meta-analysis of 6362 events among 146538 participants in 54 observational studies. European Heart Journal 2006, 27:2763-2774.

60. Kop WJ, Kuhl EA, Barasch E, Jenny NS, Gottlieb SS, Gottdiener JS: Association between depressive symptoms and fibrosis markers: the Cardiovascular Health Study. Brain, behavior, and immunity 2010, 24(2):229-35, 24(2):229-35.

61. Bremmer MA, Beekman AT, Deeg DJ, Penninx BW, Dik MG, Hack CE, Hoogendijk WJ: Inflammatory markers in late-life depression: results from a population-based study. Journal of affective disorders 2008, 106(3):249-255.

62. Ellaway A, Macintyre S: Is social participation associated with cardiovascular disease risk factors? Soc Sci Med 2007, 64(7):1384-1391.

63. Glass T, de Leon C, Marottol iR, Berkman L: Population based study of social and productive activities as predictors of survival among elderly Americans. BMJ 1999, 319(7208):478-483.

64. Glei DA, Landau D, Goldman N, Chuang Y, Rodríquez G, Weinstein M: Participating in Social Activities Helps Preserve Cognitive Function: An Analysis of a Longitudinal, Population-Based Study of the Elderly. International Journal of Epidemiology 2005, 34:864-871.

65. Bassuk S, Glass T, Berkman LF: Social disengagement and incident of cognitive decline in the community-dwelling elderly. Annals of Internal Medicine 1999, 131:165-173.

66. Cornman JC, Goldman N, Glei DA, Weinstein M, Chang M: Social Ties and Perceived Support: Two Dimensions of Social Relationships and Health among the Elderly in Taiwan. Journal of Aging and Health 2003, 15(4):616-644.

67. Rosengren A, Wilhelmsen $L$, Welin L, Tsipogianni A, Teger-Nilsson A, Wedel H: Social influences and cardiovascular risk factors as 
determinants of plasma fibrinogen concentration in a general population sample of middle aged men. BMJ 1990, 300:634-638.

68. Helminen A, Rankinen T, Väisänen S, Rauramaa R: Social network in relation to plasma fibrinogen. J Biosoc Sci 1997, 29(2):129-139.

69. Mendes de Leon C, Glass T, Berkman L: Social Engagement and Disability in a Community Population of Older Adults. American Journal of Epidemiology 2003, 157:633-642.

70. House J: Social Isolation Kills, But How and Why? Psychosomatic Medicine 2001, 63:273-274.

71. Robles T, Kiecolt-Glaser JK: The physiology of marriage: pathways to health. Physiology \& behavior 2003, 79(3):409-416.

\section{Pre-publication history}

The pre-publication history for this paper can be accessed here: http://www.biomedcentral.com/1471-2318/10/81/prepub

doi:10.1186/1471-2318-10-81

Cite this article as: Kamiya et al:: The differential impact of subjective and objective aspects of social engagement on cardiovascular risk factors. BMC Geriatrics 2010 10:81.

\section{Submit your next manuscript to BioMed Central} and take full advantage of:

- Convenient online submission

- Thorough peer review

- No space constraints or color figure charges

- Immediate publication on acceptance

- Inclusion in PubMed, CAS, Scopus and Google Scholar

- Research which is freely available for redistribution

Submit your manuscript at www.biomedcentral.com/submit 